This is the peer-reviewed version of the paper

Kuzmanović, M., Jugović, D., Mitrić, M., Jokić, B., Cvjetićanin, N., Uskoković, D., 2015. The use of various dicarboxylic acids as a carbon source for the preparation of LiFePO4/C composite. Ceramics International 41, 6753-6758. https://doi.org/10.1016/j.ceramint.2015.01.121

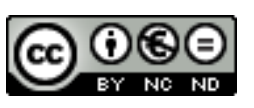

This work is licensed under a Creative Commons - Attribution-Noncommercial-No Derivative Works 3.0 Serbia 


\title{
The use of various dicarboxylic acids as a carbon source for the preparation of $\mathrm{LiFePO}_{4} / \mathrm{C}$ composite
}

Maja Kuzmanovića ${ }^{\mathrm{a}}$, Dragana Jugović ${ }^{\mathrm{a}}$, Miodrag Mitrić ${ }^{\mathrm{b}}$, Bojan Jokićc Nikola Cvjetićanin $^{\mathrm{d}}$, Dragan Uskoković ${ }^{\mathrm{a}}$

${ }^{\text {a } I n s t i t u t e ~ o f ~ T e c h n i c a l ~ S c i e n c e s ~ o f ~ S A S A, ~ K n e z ~ M i h a i l o v a ~ 35 / I V, ~} 11000$ Belgrade, Serbia

${ }^{\mathrm{b}}$ Vinča Institute of Nuclear Sciences, University of Belgrade, P.O. Box 522, 11001

Belgrade, Serbia

${ }^{c}$ Faculty of Technology and Metallurgy, University of Belgrade, Karnegijeva 4, 11000

Belgrade, Serbia

${ }^{\mathrm{d}}$ Faculty of Physical Chemistry, University of Belgrade, P.O. Box 137, Studentski trg 1216, 11158 Belgrade, Serbia

\begin{abstract}
Olivine-type $\mathrm{LiFePO}_{4}$ composite powders with carbon were synthesized by freeze drying and subsequent thermal annealing. The main purpose of the research is to explore how various dicarboxylic acids as carbon sources influence the electrochemical properties of the resulting composites. Three dicarboxylic acids (oxalic, malonic, and adipic) were used as a carbon source. The synthesis was followed by X-ray powder diffraction, scanning electron microscopy, particle-size analysis, and electrochemical experiments. It is shown that the amount of the in situ formed carbon depends on the thermal behaviour of the acids in inert atmosphere rather than on their carbon content. Cyclic voltammetry experiments and galvanostatic cycling illustrate the behaviour of different powders: the powder obtained
\end{abstract}


with oxalic acid yields the highest discharge capacity at small currents, while the one obtained with adipic acid shows better high-current response. Malonic acid has turned out to be a poor carbon source and it consequently yields powder with poor electrochemical performance.

Keywords: B. Composites; C. Diffusion; E. Electrodes; D. $\mathrm{LiFePO}_{4}$

Corresponding author: Dragana Jugović, Tel.: 381 641177549; fax: 381112185263.

E-mail addresses: dragana.jugovic@itn.sanu.ac.rs, djugovic@ vinca.rs (D. Jugović)

\section{Introduction}

Among various cathode materials, $\mathrm{LiFePO}_{4}$ has gained significant attention thanks to its good characteristics. It is characterized by high structural stability, high theoretical capacity $\left(170 \mathrm{mAhg}^{-1}\right)$, very flat voltage curve around $3.4 \mathrm{~V}$ versus $\mathrm{Li} / \mathrm{Li}^{+}$, low self discharge at elevated temperatures, low cost and low toxicity. However, $\mathrm{LiFePO}_{4}$ has some disadvantages, including low electronic conductivity $\left(10^{-8}-10^{-10} \mathrm{~S} \mathrm{~cm}^{-1}\right)[1]$ and slow lithium ion diffusion in the solid phase [2]. To overcome these problems, many approaches have been proposed such as: decreasing the particle size [3], which can significantly shorten the diffusion path for $\mathrm{Li}^{+}$ions; conductive surface coating of $\mathrm{LiFePO}_{4}$ which can 
increase the electronic conductivity of the material [4-7]; and ion doping [8-10], which may increase the intrinsic electronic conductivity. These approaches can be implemented using different synthesis methods, such as solid-state, sol-gel, hydrothermal, spray pyrolysis, precipitation, mechanochemical activation, microwave processing etc. $[11,12]$. The synthesis method also has a great influence on the phase purity, particle size and morphology, which greatly influence electrochemical performance. The freeze drying process has often been used for the synthesis of ceramics, superconducting materials, biomedical materials and hard alloys [13]. It has also been used for the preparation of $\mathrm{LiFePO}_{4} / \mathrm{C}$ composites [14-20], which involve various carbon-containing precursors as a carbon source: citric acid [15], formic acid [16,17], oxalic acid [18,19], gelatine [20,21], etc. The main advantage of this preparation process is mixing at the atomic level, which yields a more homogeneous precursor powder.

In this study, we report the synthesis of $\mathrm{LiFePO}_{4} / \mathrm{C}$ composites by freeze-drying a precursor solution and subsequent thermal annealing. Three dicarboxylic acids (oxalic, malonic and adipic) were used both as a carbon source and an acidic medium that prevented the oxidation of $\mathrm{Fe}^{2+}$ ions in the precursor solution.

\section{Materials and Methods}

The $\mathrm{LiFePO}_{4} / \mathrm{C}$ composites were obtained using freeze-drying and thermal annealing. The starting materials were lithium hydroxide monohydrate $\left(\mathrm{LiOH} \cdot \mathrm{H}_{2} \mathrm{O}\right)$, ferrous sulphate heptahydrate $\left(\mathrm{FeSO}_{4} \cdot 7 \mathrm{H}_{2} \mathrm{O}\right)$ and diammonium hydrogenphosphate $\left(\left(\mathrm{NH}_{4}\right)_{2} \mathrm{HPO}_{4}\right)$, which were mixed in the 1:1:1 molar ratio. Three dicarboxylic acids with different chain lengths, 
oxalic, malonic and adipic, were used as a carbon source. These acids also prevent ferrous ion oxidation by creating an acidic medium. $\mathrm{FeSO}_{4}$ was first dissolved in distilled water, and then one of the acids was added in the 1:1 molar ratio. Separately prepared water solutions of $\mathrm{LiOH}$ and $\left(\mathrm{NH}_{4}\right)_{2} \mathrm{HPO}_{4}$ were added to the previous solution and stirred for an hour. The obtained suspensions were frozen at $-15^{\circ} \mathrm{C}$ and subsequently subjected to freezedrying at $-50{ }^{\circ} \mathrm{C}$ for 20 hours in a Christ Alpha 1-2 LDplus freeze dryer. The solid precursors were calcined at $650{ }^{\circ} \mathrm{C}$ for three hours in $\mathrm{Ar} / \mathrm{H}_{2}(5 \%)$ atmosphere. The samples prepared with oxalic, malonic and adipic acids were denoted as LFP-OA, LFP-MA and LFP-AA, respectively.

The X-ray powder diffraction measurements were performed on a Philips PW 1050 X-ray powder diffractometer using Ni-filtered $\mathrm{Cu}-\mathrm{K}_{1,2}(\lambda=1.54178 \AA)$ radiation and the BraggBrentano focusing geometry. Measurements were done at room temperature over the 2è range of $10-70^{\circ}$ with a scanning step width of $0.05^{\circ}$ and a counting time of $3 \mathrm{~s}$ per step. The morphology of the synthesized powder was analyzed by scanning electron microscopy (TESCAN, MIRA3 XMU) at $20 \mathrm{kV}$.

The particle-size distributions were determined by a particle-size analyzer (PSA) Mastersizer 2000 (Malvern Instruments Ltd., UK). For the purpose of particle-size measurements, the powder was dry deagglomerated in an ultrasonic bath (frequency of 40 $\mathrm{kHz}$ and power of $50 \mathrm{~W}$ ) for $30 \mathrm{~min}$.

The thermal behaviour was determined by simultaneous TG-DTA (Setsys, SETARAM Instrumentation, Caluire, France) in the temperature range between $25^{\circ} \mathrm{C}$ and $800{ }^{\circ} \mathrm{C}$ in argon or air flow, in an alumina pan at a constant heating rate of $10^{\circ} \mathrm{C} \mathrm{min}^{-1}$. 
The electrochemical charge/discharge tests were carried out using a two electrode-cell with metallic lithium as a counter electrode and $1 \mathrm{M} \mathrm{LiClO}_{4}$ in $\mathrm{PC}$ as an electrolyte. The working electrode, supported onto platinum foil, was a mixture containing the synthesized material, carbon black and PVdF in the ratio 75:15:10. The electrochemical cells were assembled in an argon-filled glove box. The galvanostatic charge/discharge tests were performed between 2.3 V and 4.1 V at different current rates, using the Arbin BT 2042 battery test system. Cyclic voltammetry experiments were carried out using a Gamry PCI4/300 Potentiostat/Galvanostat device. The three-electrode cell consisted of a working electrode, a wide platinum foil as a counter electrode, and a saturated calomel electrode (SCE) as a reference electrode. The electrolyte solution was a saturated aqueous solution of $\mathrm{LiNO}_{3}$.

\section{Results and Discussion}

The crystal structure of the synthesized powders was confirmed by X-ray powder diffraction. The diffraction patterns (Fig. 1) reveal a $\mathrm{LiFePO}_{4}$ phase of the olivine type structure (JCPDS No. 40-1499). There is no evidence for the formation of crystalline carbon; accordingly, internal carbon can be treated as a contribution to the background. The X-ray Line Profile Fitting Program (XFIT) with a Fundamental Parameters convolution approach to generating line profiles [22] was used for the calculation of both the crystallite size and the microstrain parameter of the synthesized powders (Table 1). The microstructural data indicate that the procedure itself is suitable for obtaining powders with small crystallite sizes. The amount of the in situ formed carbon was determined thermogravimetrically. The decomposition of oxalic and adipic acids produced the carbon 
residue of $2 \mathrm{wt} \%$ and $3 \mathrm{wt} \%$, respectively, while no carbon residue was found in the sample synthesized with malonic acid.

Scanning electron microscopy revealed different morphologies of the powders when different acids were used as a carbon source (Fig. 2a-c). The most distinct morphology was evidenced when malonic acid was used: a jigsaw puzzle-like morphology with sintered particles with no clearly visible boundaries. Such morphology is similar to the morphology typically found in $\mathrm{LiFePO}_{4}$ powders prepared by the solid-state reaction [23]. On the other hand, the particles of the powders obtained using oxalic and adipic acids were round and agglomerated. The particle-size distributions of these two powders (Fig. 3) have lognormal shape with a high degree of uniformity, showing close span values and an average particle size of 535 and $412 \mathrm{~nm}$, respectively (Table 1). Apparently, the observed agglomerates from the SEM images are not strongly bonded and they easily deagglomerate under ultrasonic agitation, which is normally involved in the PSA experiment. It is important to note here that the powder obtained with malonic acid, the one without residual carbon, showed a bimodal particle size distribution by volume. This implies the presence of particles with either two different sizes, or with a morphology in which one dimension is prolonged. Therefore, the PSA results for the powder obtained with malonic acid are not reliable. The particle size of this powder, estimated from the SEM image, is ca. $1 \mu \mathrm{m}$. A comparison of the average particle size and the mean crystallite size, determined from the X-ray diffraction data, indicates a polycrystalline nature of the particles. Three dicarboxylic acids used in this study have a common formula $\mathrm{HOOC}\left(\mathrm{CH}_{2}\right)_{n} \mathrm{COOH}(\mathrm{n}=0,1$, and 4 , for oxalic, malonic, and adipic acid, respectively) and differ from each other in chain lengths, which results in different thermal behaviours [24]. Fig. 4 shows the TG/DTA curves of the 
chemicals used in this study. The melting and the decomposition processes in malonic acid occur within a $10{ }^{\circ} \mathrm{C}$ range at low temperatures, oxalic acid sublimes and then decomposes, while adipic acid melts and decomposes at higher temperatures within a wider temperature range. This leads to different mechanisms of particle growth and different carbon content in the powders.

The galvanostatic cycling measurements were done under the same current rate, both for charging and discharging processes. The charge/discharge rates are given in $\mathrm{C} / n$, where $\mathrm{C}$ is the nominal capacity equal to $170 \mathrm{mAh}$ per gram of active material $\left(\mathrm{LiFePO}_{4}\right)$, and $n$ is the time, given in hours, needed for the complete charge/discharge. The initial charge/discharge curves at a small current rate (C/10), given in Fig. 5, show a characteristic flat voltage plateau at around 3.4 V. The values of the specific capacities for the first discharging are 152, 97 and 112mAh/g for LFP-OA, LFP-MA and LFP-AA, respectively. The cycling performances at variable discharge rates from $\mathrm{C} / 10$ to $3 \mathrm{C}$ are presented in Fig. 6. The electrodes that are prepared with carbon-coated $\mathrm{LiFePO}_{4}$ particles (LFP-OA and LFP-AA) show a good rate capability and an excellent cycling stability. On the other hand, the electrode prepared with no carbon-containing particles (LFP-MA) shows a dramatic drop of the discharge capacity. This implies that, within this range of particle sizes, carbon coating is an efficient way to overcome the transport limitations of the olivine structure mentioned in the introductory part. However, when higher currents are applied, the particle size has a greater influence: at $2 \mathrm{C}$ and higher rates, the LFP-AA powder with smaller particles and smaller microstructural parameters (crystallite size and microstrain), shows a greater specific capacity than the sample LFP-OA. A relatively small amount of carbon in 
composite powders indicates that both oxalic and adipic acids were a good choice for the carbon source.

The cyclic voltammetry experiments were performed in an aerated saturated aqueous solution of $\mathrm{LiNO}_{3}$, in the voltage range from 0.4 to $1 \mathrm{~V}$ versus SCE with scan rates 1,10 , and $50 \mathrm{mVs}^{-1}$. The characteristic of all CV curves is the presence of only one pair of redox peaks that can be attributed to the two-phase reaction between the lithiated phase, $\mathrm{LiFePO}_{4}$, and the delithiated phase, $\mathrm{FePO}_{4}$ (Fig. 7a-c). Accordingly, the presence of any other electroactive species is excluded. A significantly reduced peak separation and increased current response, observed for the sample obtained with adipic acid, indicate significantly faster kinetics already noticed in the galvanostatic regime. The low-current response of the sample prepared with malonic acid is also in accord with the findings of the galvanostatic measurements.

\section{Conclusion}

Olivine type $\mathrm{LiFePO}_{4}$ composites with carbon were synthesized by freeze drying and subsequent thermal annealing. Three dicarboxylic acids (oxalic, malonic, and adipic) were used as a carbon source. It has been shown that the amount of the in situ formed carbon depends on the thermal behaviour of the acids in inert atmosphere rather than on their carbon content. During galvanostatic cycling the powders behaved differently: at moderate currents, the powder synthesized with oxalic acid delivered higher capacity than the one

obtained with adipic acid; at higher currents, the powder obtained with adipic acid showed 
a greater capacity. Malonic acid turned out to be a poor carbon source, which was reflected in the poor electrochemical performance of the obtained composite.

\section{Acknowledgements}

The Ministry of Education, Science and Technological Development of the Republic of Serbia provided financial support for this study under grants nos. III 45004 and III 45015.

\section{References}

[1] M.S. Whittingham, Lithium Batteries and Cathode Materials, Chem. Rev. 104 (2004) 4271-4302.

[2] P.P. Prosini, M. Lisi, D. Zane, M. Pasquali, Determination of the chemical diffusion coefficient of lithium in $\mathrm{LiFePO}_{4}$, Solid State Ion. 148 (2002) 45-51.

[3] A. Vadivel Murugan, T. Muraliganth, A. Manthiram, Rapid microwave-solvothermal synthesis of phospho-olivine nanorods and their coating with a mixed conducting polymer for lithium ion batteries, Electrochem. Commun. 10 (2008) 903-906.

[4] Y.-G. Huang, F.-H. Zheng, X.-H. Zhang, Q.-Y. Li, H.-Q. Wang, Effect of carbon coating on cycle performance of $\mathrm{LiFePO}_{4} / \mathrm{C}$ composite cathodes using Tween80 as carbon source, Electrochimica Acta. 130 (2014) 740-747.

[5] J. Lee, P. Kumar, B.M. Moudgil, R.K. Singh, Electrochemical enhancement of $\mathrm{LiFePO}_{4}$ as a cathode material by incorporating $\mathrm{Cu}$ flakes for lithium ion rechargeable battery, Solid State Ion. 231 (2013) 18-24. 
[6] Y. Qiu, Y. Geng, J. Yu, X. Zuo, High-capacity cathode for lithium-ion battery from $\mathrm{LiFePO}_{4} /\left(\mathrm{C}+\mathrm{Fe}_{2} \mathrm{P}\right)$ composite nanofibers by electrospinning, J. Mater. Sci. 49(2014) 504-509.

[7] C.H. Mi, Y.X. Cao, X.G. Zhang, X.B. Zhao, H.L. Li, Synthesis and characterization of $\mathrm{LiFePO}_{4} /(\mathrm{Ag}+\mathrm{C})$ composite cathodes with nano-carbon webs, Powder Technol. 181 (2008) 301-306.

[8] C.S. Sun, Z. Zhou, Z.G. Xu, D.G. Wang, J.P. Wei, X.K. Bian, et al., Improved highrate charge/discharge performances of $\mathrm{LiFePO}_{4} / \mathrm{C}$ via V-doping, J. Power Sources. 193 (2009) 841-845.

[9] H. Shu, X. Wang, Q. Wu, B. Hu, X. Yang, Q. Wei, et al., Improved electrochemical performance of $\mathrm{LiFePO}_{4} / \mathrm{C}$ cathode via $\mathrm{Ni}$ and $\mathrm{Mn}$ co-doping for lithium-ion batteries, J. Power Sources. 237 (2013) 149-155.

[10] J. Song, G. Shao, M. Shi, Z. Ma, W. Song, C. Wang, et al., The effect of doping Co on the electrochemical properties of $\mathrm{LiFePO}_{4} / \mathrm{C}$ nanoplates synthesized by solvothermal route, Solid State Ion. 253 (2013) 39-46.

[11] W.-J. Zhang, Structure and performance of $\mathrm{LiFePO}_{4}$ cathode materials: A review, J. Power Sources. 196 (2011) 2962-2970.

[12] D. Jugović, D. Uskoković, A review of recent developments in the synthesis procedures of lithium iron phosphate powders, J. Power Sources. 190 (2009) 538-544.

[13] G.W. Oetjen, P. Haseley, Freeze drying, second ed., Wiley-VCH, Weinheim, (2004).

[14] V. Palomares, A. Goñi, I.G. de Muro, I. de Meatza, M. Bengoechea, O. Miguel, et al., New freeze-drying method for LiFePO4 synthesis, J. Power Sources. 171 (2007) 879885. 
[15] V. Palomares, A. Goñi, I.G. de Muro, I. de Meatza, M. Bengoechea, I. Cantero, et al., Influence of Carbon Content on $\mathrm{LiFePO}_{4}$ / C Samples Synthesized by Freeze-Drying Process, J. Electrochem. Soc. 156 (2009) A817-A821.

[16] V. Koleva, E. Zhecheva, R. Stoyanova, A new phosphate-formate precursor method for the preparation of carbon coated nano-crystalline $\mathrm{LiFePO}_{4}$, J. Alloys Compd. 476 (2009) 950-957.

[17] E. Zhecheva, M. Mladenov, P. Zlatilova, V. Koleva, R. Stoyanova, Particle size distribution and electrochemical properties of $\mathrm{LiFePO}_{4}$ prepared by a freeze-drying method, J. Phys. Chem. Solids. 71 (2010) 848-853.

[18] Y. Cui, X. Zhao, R. Guo, High rate electrochemical performances of nanosized ZnO and carbon co-coated $\mathrm{LiFePO}_{4}$ cathode, Mater. Res. Bull. 45 (2010) 844-849.

[19] Y. Cui, X. Zhao, R. Guo, Improved electrochemical performance of $\mathrm{La}_{0.7} \mathrm{Sr}_{0.3} \mathrm{MnO}_{3}$ and carbon co-coated $\mathrm{LiFePO}_{4}$ synthesized by freeze-drying process, Electrochimica Acta. 55 (2010) 922-926.

[20] N. Liu, M. Gao, Z. Li, C. Li, W. Wang, H. Zhang, et al., Effect of gelatin concentration on the synthetize of the $\mathrm{LiFePO}_{4} / \mathrm{C}$ composite for lithium ion batteries, J. Alloys Compd. 599 (2014) 127-130.

[21] M. Gao, N. Liu, Z. Li, W. Wang, C. Li, H. Zhang, et al., A gelatin-based sol-gel procedure to synthesize the $\mathrm{LiFePO}_{4} / \mathrm{C}$ nanocomposite for lithium ion batteries, Solid State Ion. 258 (2014) 8-12.

[22] R.W. Cheary, A. Coelho, A fundamental parameters approach to X-ray line-profile fitting, J. Appl. Crystallogr. 25 (1992) 109-121. 
[23] D. Jugović, N. Cvjetićanin, M. Mitrić, S. Mentus, Comparison between Different $\mathrm{LiFePO}_{4}$ synthesis routes, Mater. Sci. Forum. 555 (2007) 225-230.

[24] K. Muraishi, Y. Suzuki, The thermal behaviour of dicarboxylic acids in various atmospheres, Thermochim. Acta. 232 (1994) 195-203.

Table 1 - The mean crystallite size, microstrain, mean particle size, span and carbon content for $\mathrm{LiFePO}_{4}$ powders obtained with oxalic, malonic and adipic acid

\begin{tabular}{llllll}
\hline & $\begin{array}{l}\text { mean crystallite } \\
\text { size }[\mathrm{nm}]\end{array}$ & microstrain & mean particle & span & carbon content \\
& {$[\%]$} & size $[\mathrm{nm}]$ & & {$[\mathrm{wt} . \%]$} \\
\hline Oxalic & 41 & 0.17 & 535 & 1.3 & 2 \\
Malonic & 38 & 0.14 & $\mathrm{n} / \mathrm{a}$ & $\mathrm{n} / \mathrm{a}$ & 0 \\
Adipic & 35 & 0.15 & 412 & 1.4 & 3 \\
\hline
\end{tabular}




\section{Figure captions}

Fig. 1 - XRD patterns of $\mathrm{LiFePO}_{4}$ powders synthesized with oxalic, malonic and adipic acid.

Fig. 2 - SEM images of $\mathrm{LiFePO}_{4}$ powders obtained with a) oxalic, b) malonic, and c) adipic acid.

Fig. 3 - Particle size distributions for $\mathrm{LiFePO}_{4}$ powders obtained with oxalic and adipic acid.

Fig.4 - TG-DTA curves of dicarboxylic acids in flowing argon.

Fig. 5 - The initial charge/discharge curves at $\mathrm{C} / 10$ for $\mathrm{LiFePO}_{4}$ prepared with oxalic, malonic and adipic acid.

Fig. 6 - Cyclic performance of $\mathrm{LiFePO}_{4}$ powders prepared with oxalic, malonic and adipic acid at different current rates from $\mathrm{C} / 10$ to $3 \mathrm{C}$.

Fig. 7 - Cyclic volatmmograms of $\mathrm{LiFePO}_{4}$ prepared with oxalic, malonic and adipic acid with a scan rate of $1 \mathrm{mVs}^{-1}(\mathrm{a}), 10 \mathrm{mVs}^{-1}$ (b), $50 \mathrm{mVs}^{-1}$ (c) 


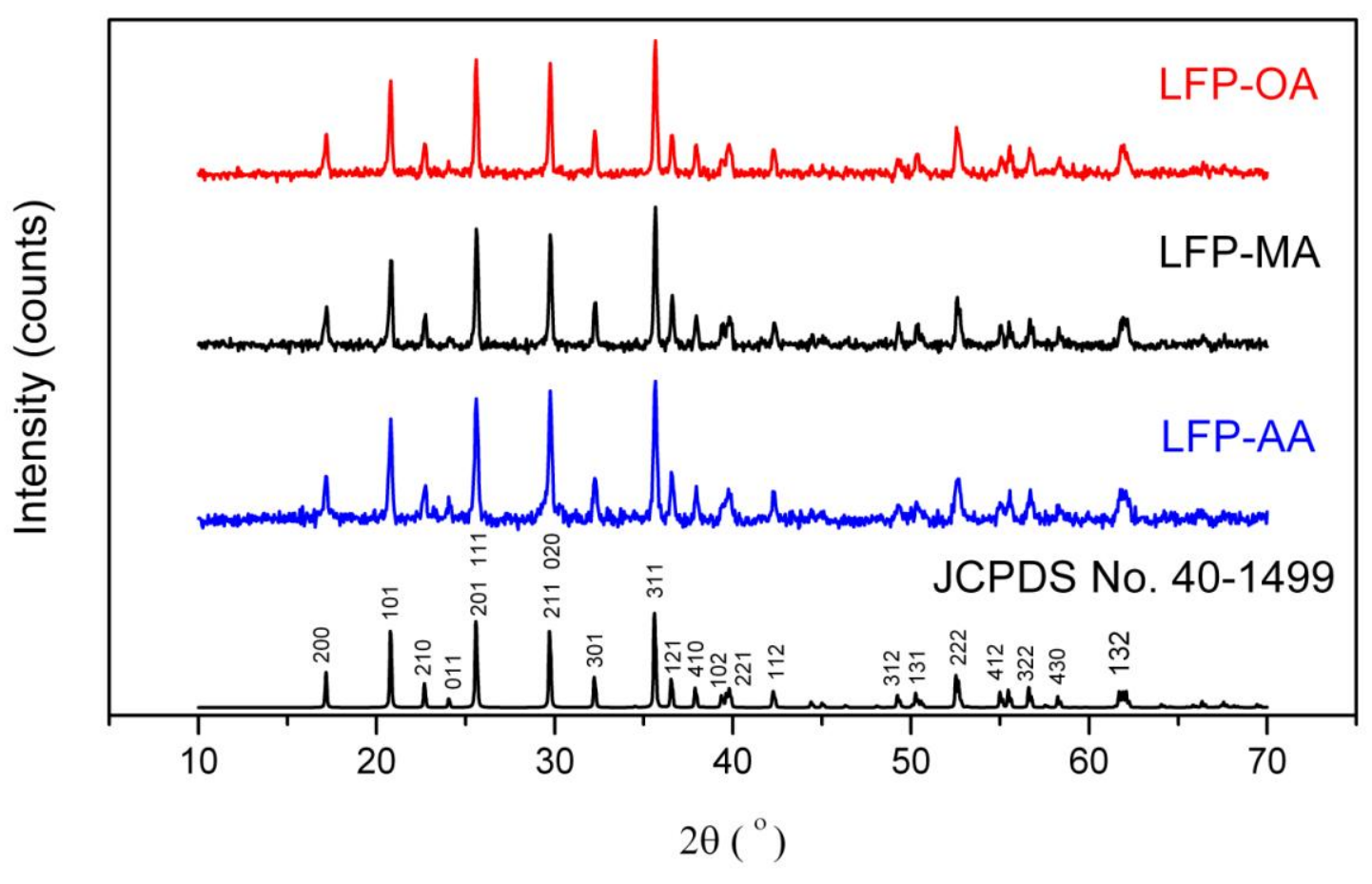

Fig. 1 


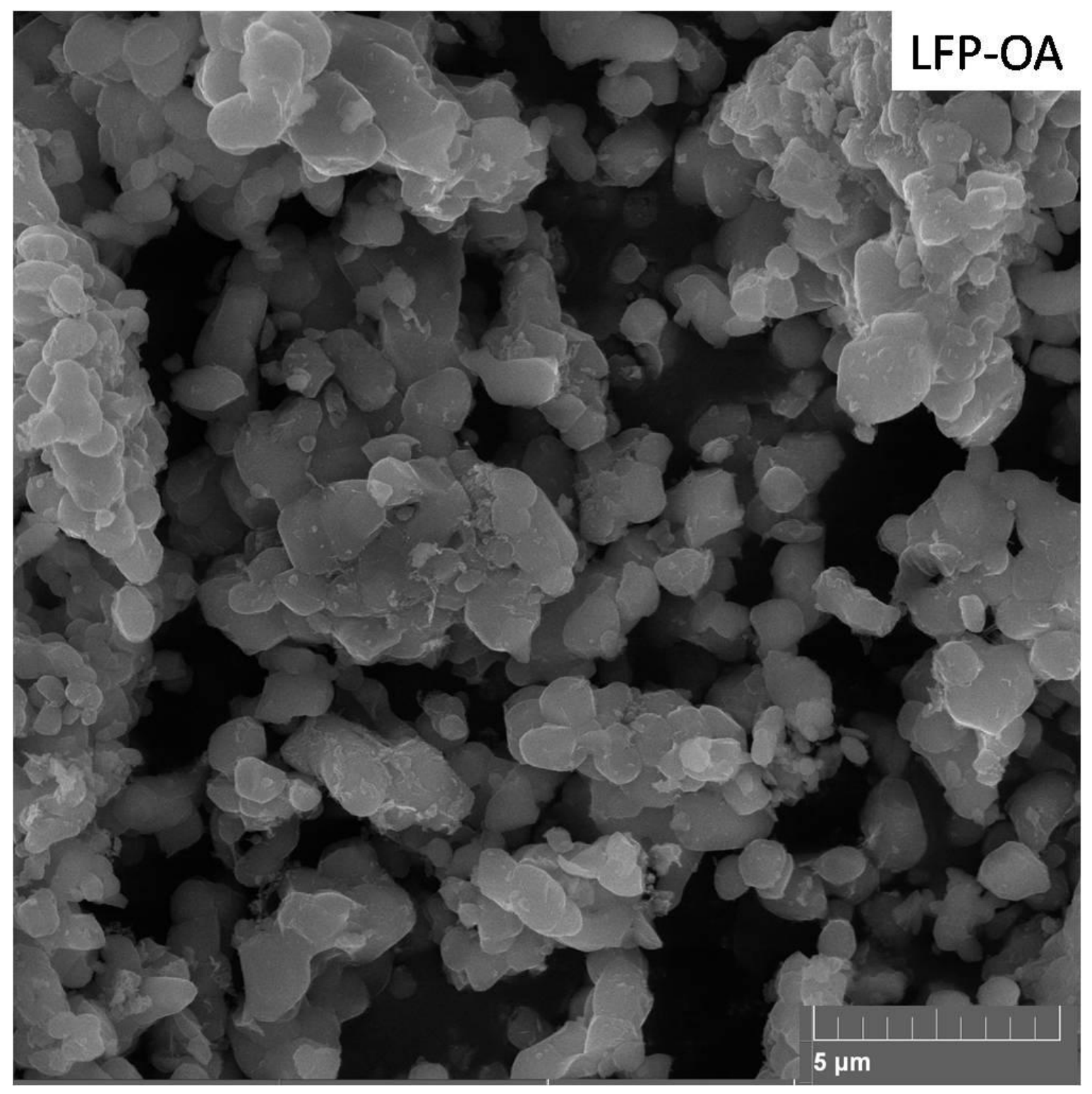

Fig. 2a 


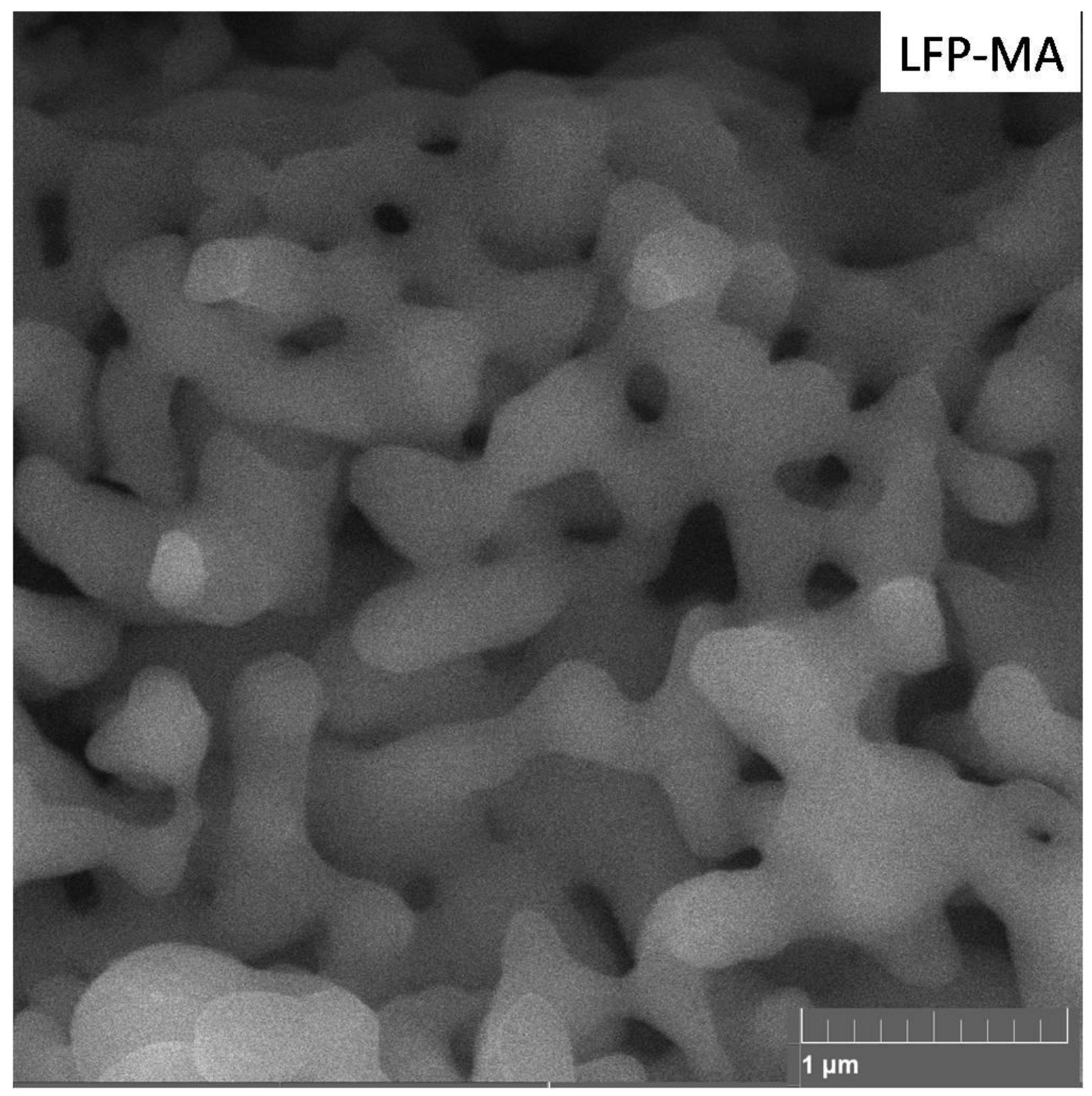

Fig. 2b 


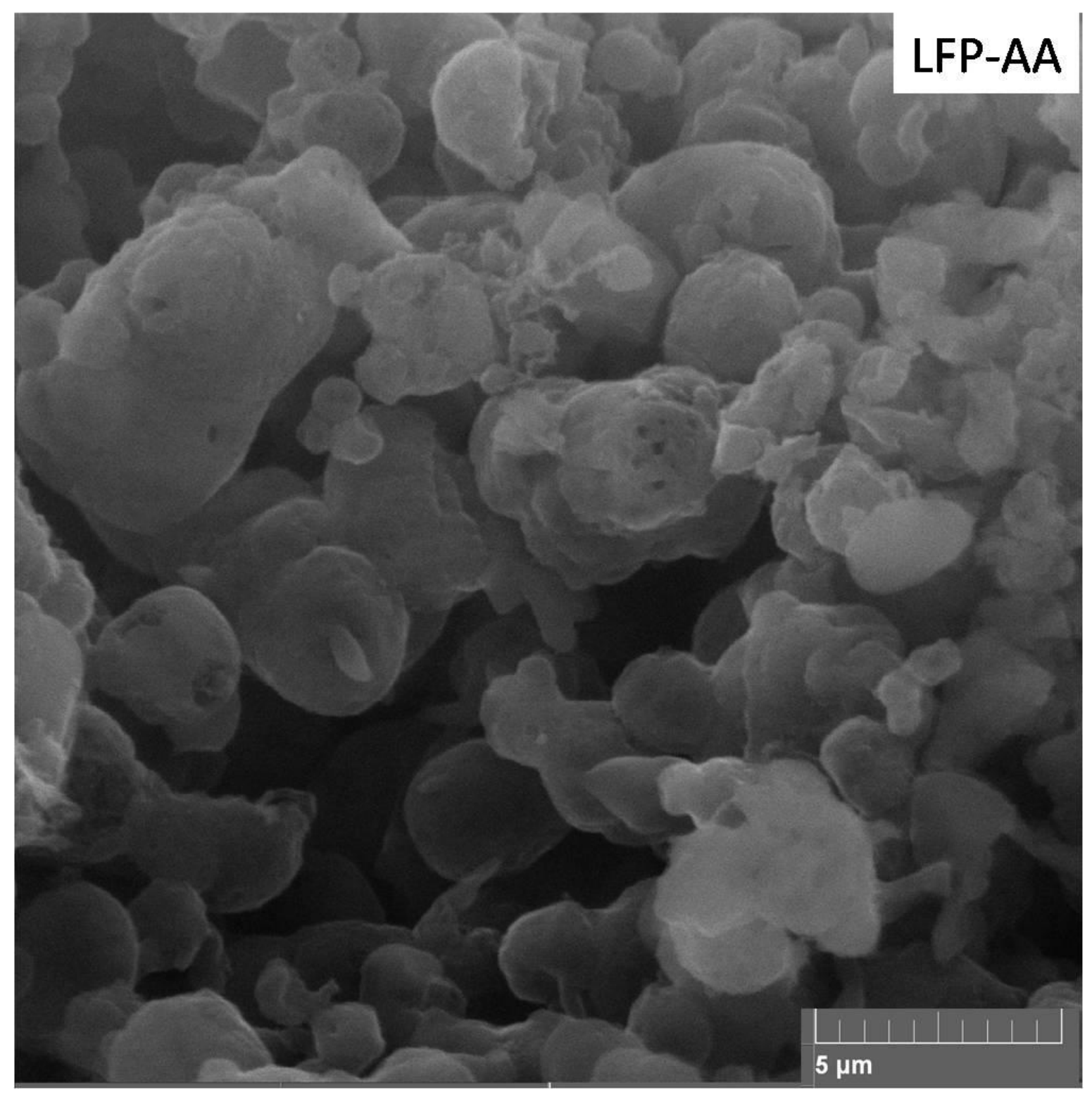

Fig. 2c 


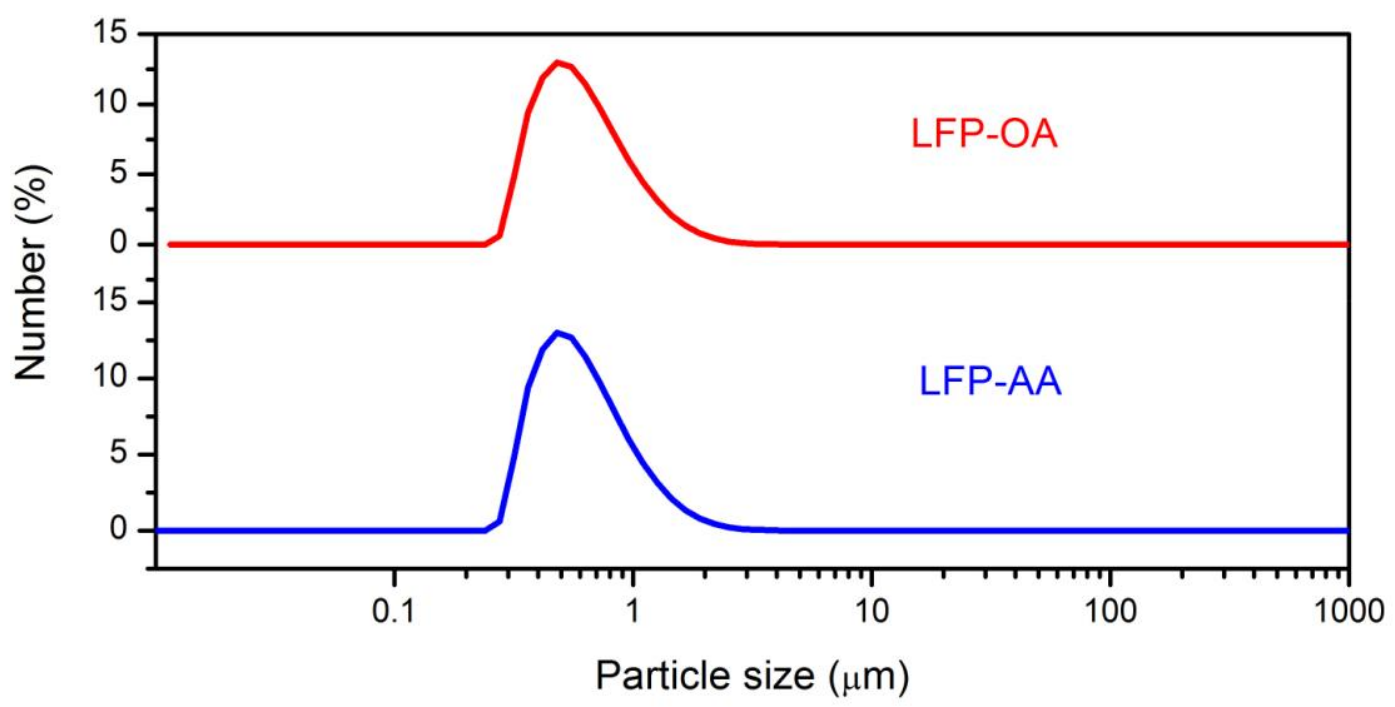

Fig. 3 


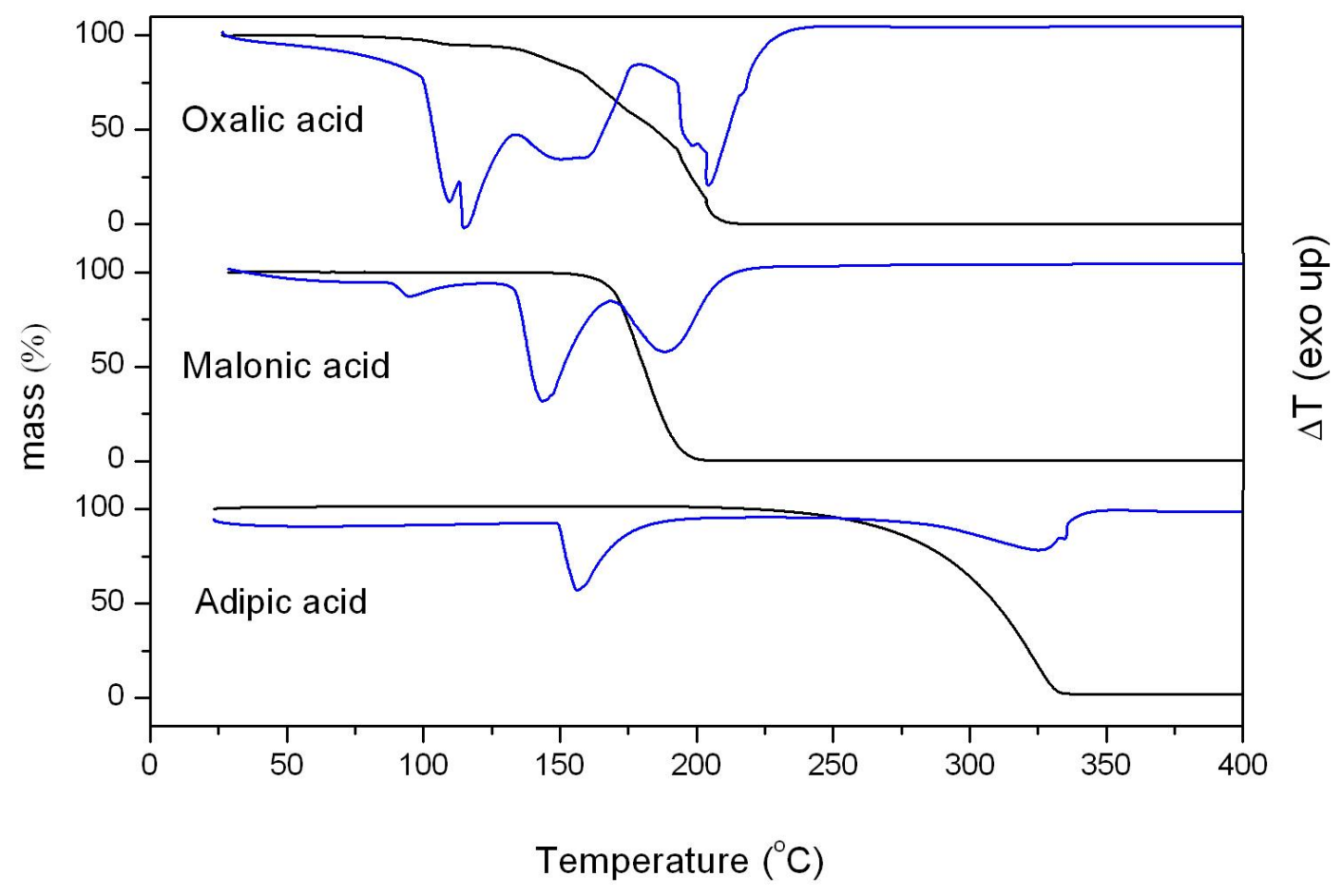

Fig. 4 


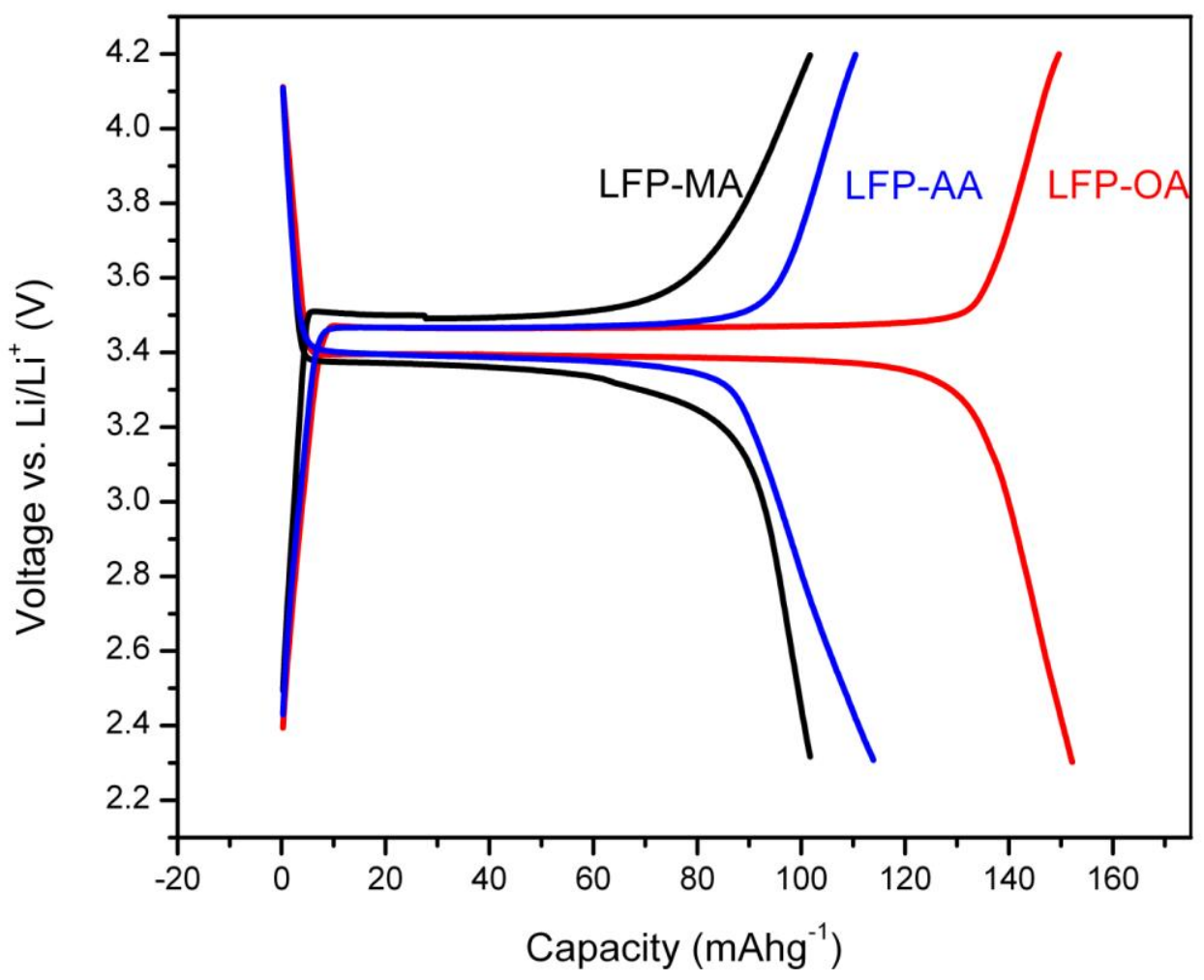

Fig. 5 


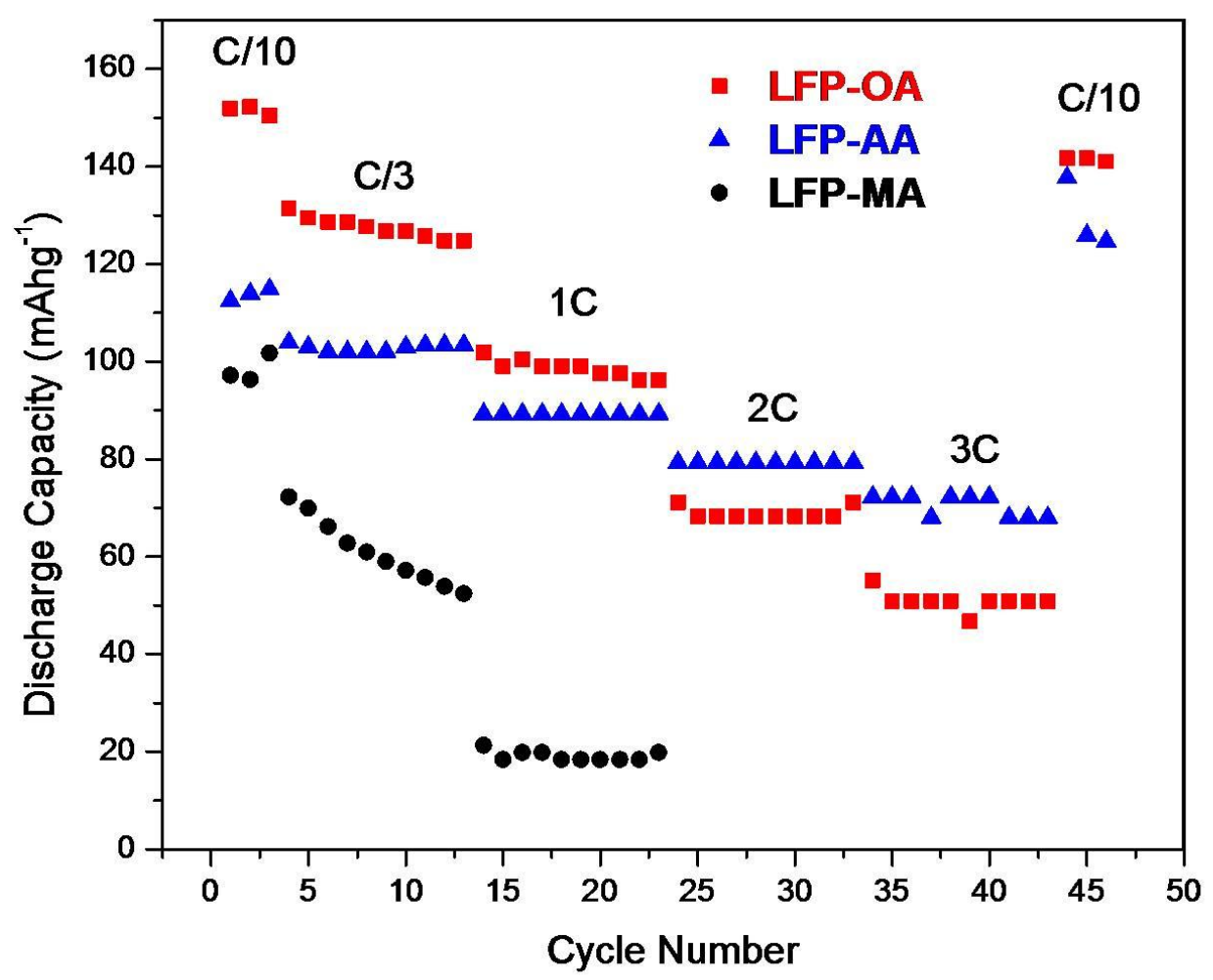

Fig. 6 


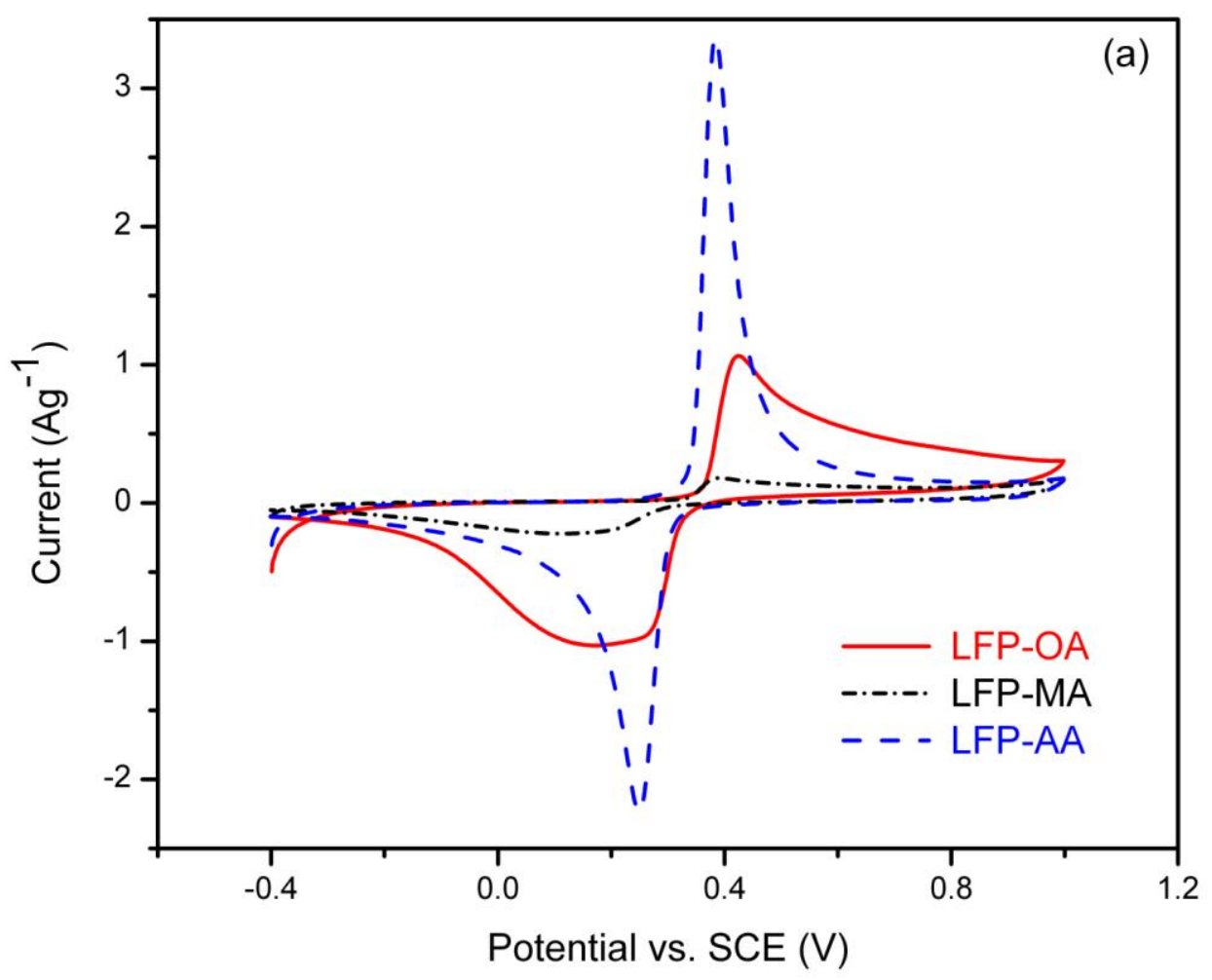

Fig. 7a 


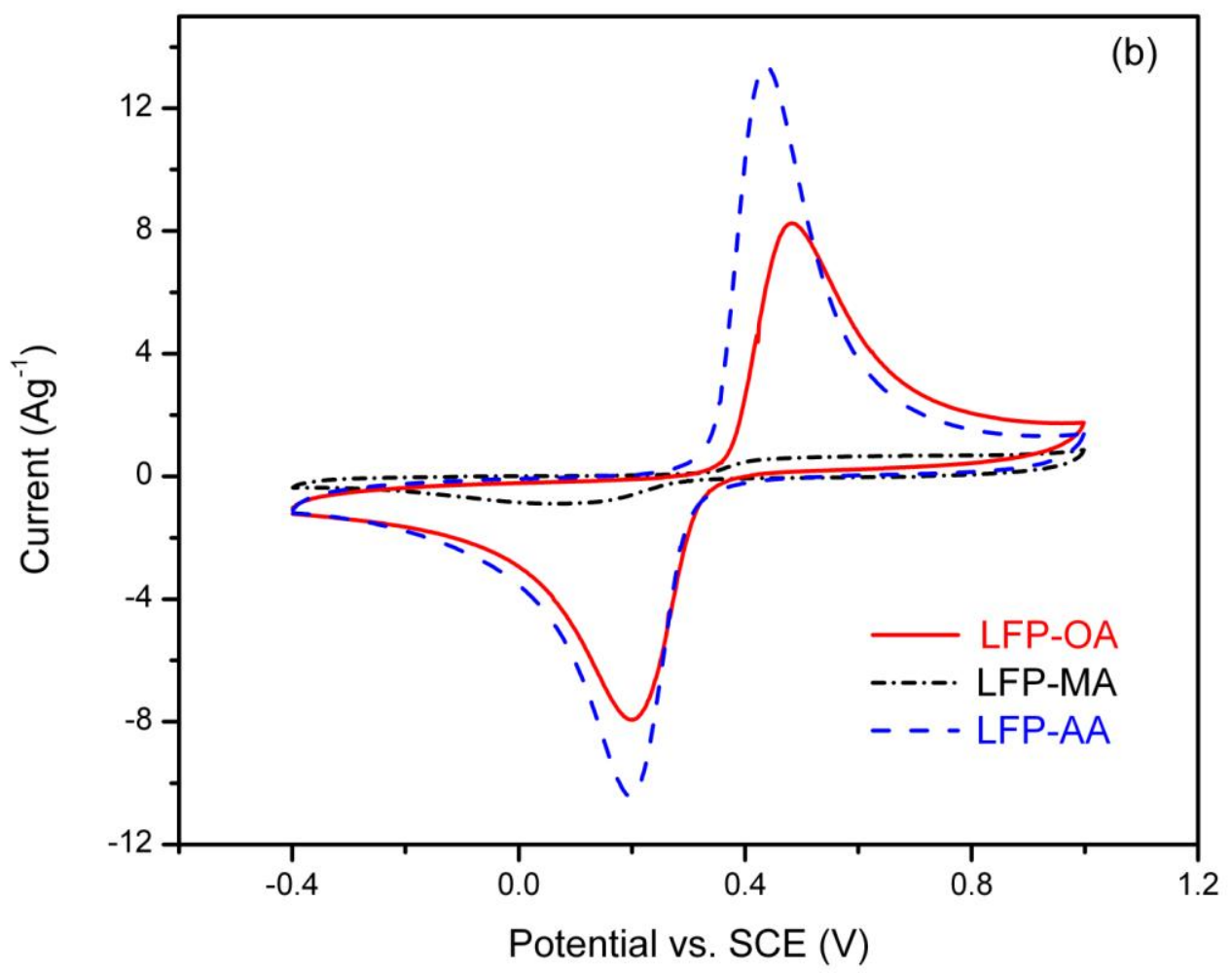

Fig. 7b 


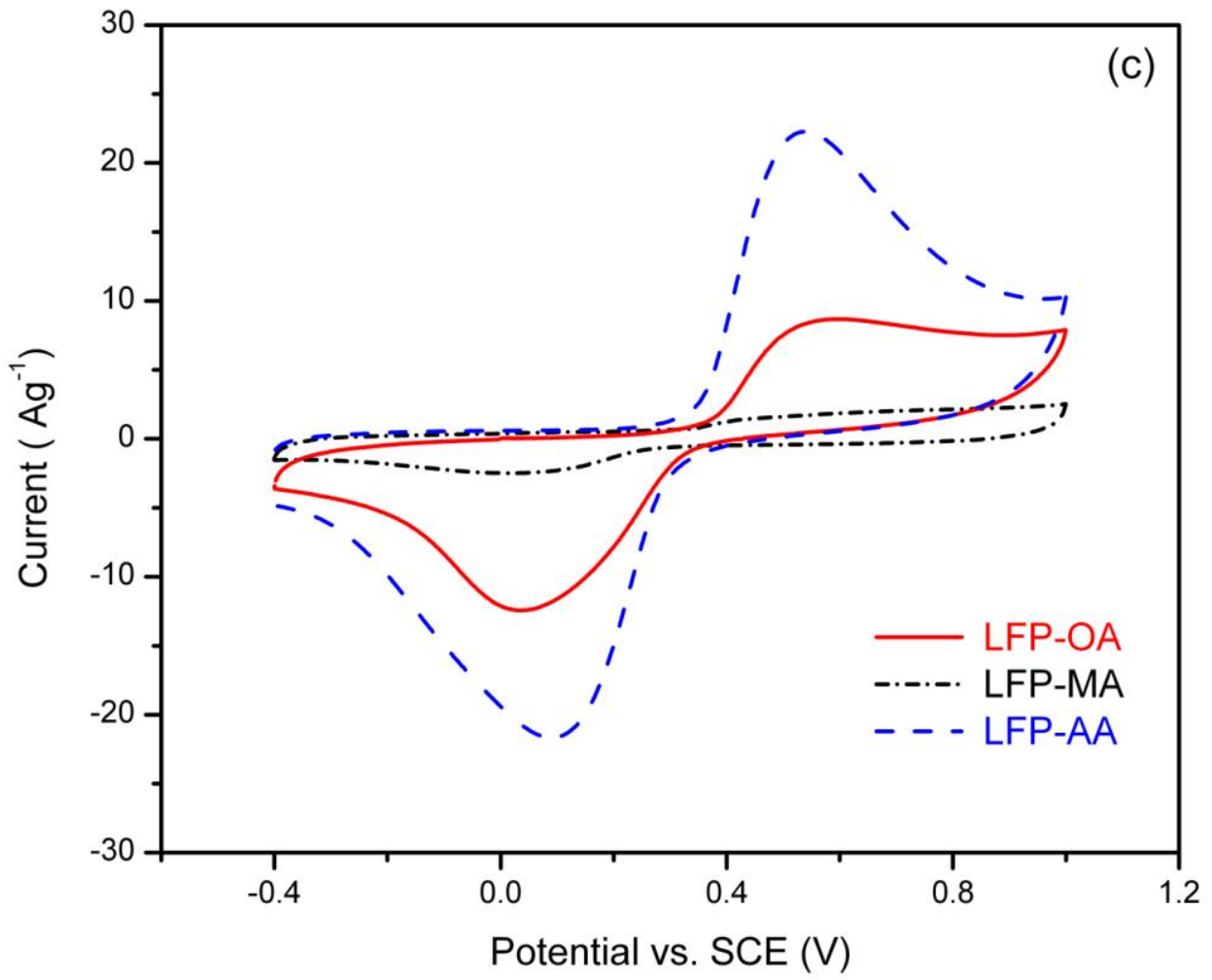

Fig. 7c 